\title{
Influence of the Manufacturing Process of a Claw-Pole Alternator on its Stator Shape and Acoustic Noise
}

\author{
Antoine Tan-Kim, Nicolas Hagen, Vincent Lanfranchi, Stéphane Clénet, Thierry Coorevits, \\ Jean-Claude Mipo, Jérôme Legranger and Frédéric Palleschi
}

\begin{abstract}
This paper shows the influence of the manufacturing process of a claw-pole alternator on its acoustic noise. First, the stator welds and the assembly of the stator in the brackets are linked to deformations of the inner diameter of the stator. Then, the influences of these deformations on the magnetic forces and the subsequent acoustic noise are investigated. Results show that the deformations caused by the manufacturing process significantly increase the sound power level of particular orders.
\end{abstract}

Index Terms-Acoustic noise, claw-pole alternator, manufacturing tolerances, faults

\section{INTRODUCTION}

Claw-pole alternators are complex electrical machines not only due to their rotor shape but also because of their assembly as shown in Figure 1. Assembling these parts together as well as manufacturing the parts lead to discrepancies between nominal and real shapes and dimensions. Manufacturing tolerances and process have an influence on torque ripple or back EMF for permanent magnet synchronous machines [2],[3],[4]. Acoustic noise of electrical machines can also be influenced by tolerances on material parameters [5] or dimensions. The most common studied fault is eccentricity [6], [7]. However, other tolerances, such as stator deformations, can change the airgap width and also affect the performances and the acoustic noise of electrical machines.

Liu [8] has investigated the influence of stator deformations of a claw-pole alternator on its no-load flux linkage and torque. A stator with an oval shape as well as a stator with retracted teeth at specific locations were studied. The oval shape was found to have little influence on the noload characteristics whereas the retracted teeth have a greater

Paper presented at the XXII International Conference on Electrical Machines (ICEM), Lausanne, September 4-7, 2016 [1]

A. Tan-Kim, J.C. Mipo, J. Legranger and F. Palleschi are with Valeo Engine and Electrical Systems, Créteil, France (e-mail: antoine.tankim@valeo.com).

N. Hagen is with Arts et Métiers ParisTech, Centre de Paris, 151 boulevard de l'hopital, 75013 Paris, France.

V. Lanfranchi is with Sorbonne University, Université de Technologie de Compiègne, EA 1006 Laboratoire Electromécanique, Compiègne, France (email: vincent.lanfranchi@utc.fr).

S. Clénet is with L2EP, Arts et Métiers ParisTech, Centre de Lille, 8 boulevard Louis XIV - 59046 Lille Cedex, France.

T. Coorevits is with MSMP, Arts et Métiers ParisTech, Centre de Lille, 8 boulevard Louis XIV - 59046 Lille Cedex, France. influence especially on the cogging torque. Offermann et al. [9] also studied these machine uncertainties and found a link between the retracted teeth and the $12^{\text {th }}$ and $24^{\text {th }}$ harmonics of the cogging torque. Ramesohl [10] found, by simulation, that an oval stator with a maximum increase of $0.1 \mathrm{~mm}$ of the airgap width significantly increases the sound power level of the $5^{\text {th }}$ and $6^{\text {th }}$ harmonics (assumed to be the $30^{\text {th }}$ and $36^{\text {th }}$ orders in this study) but the faults were not implemented in a full finite element simulation. To the author's knowledge, the influence of retracted teeth on the acoustic noise has not been investigated.

This paper aims at investigating the influence of stator deformations on the acoustic noise of claw-pole alternators. It establishes a link between the stator deformations shown in [8] and the simulation of acoustic noise of claw-pole alternators shown in [12]. First, the influence of the manufacturing process on the stator deformations is explained. This model uses permeance functions and magnetomotive force (MMF) functions taking into account 3D rotor topology and stator deformations. Then, electromagnetic and vibroacoustic simulations are carried out taking these deformations into account. Finally, the influence of the deformations on the magnetic forces and the sound power level are analyzed.

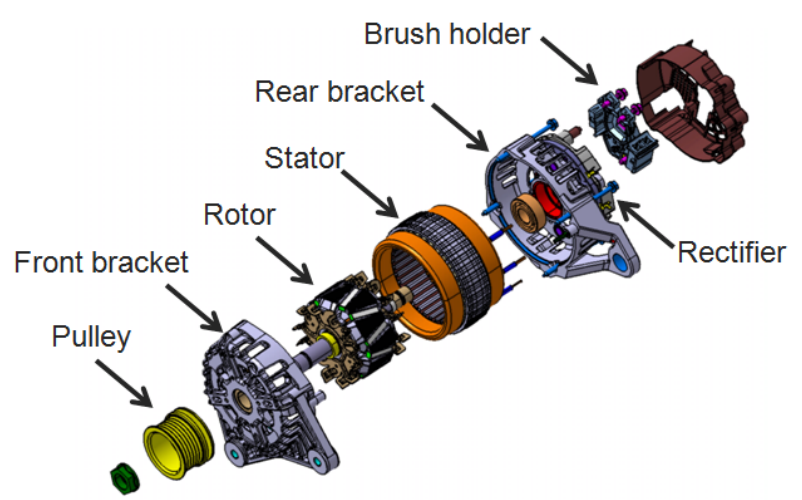

Figure 1: Exploded view of an alternator [12] 


\section{INFLUENCE OF THE MANUFACTURING PROCESS ON THE STATOR SHAPE}

The manufacturing process of a claw-pole alternator introduces two specific deformations of the stator.

The first deformation is due to the stator manufacturing. The stator stack of a claw-pole alternator is made up with an assembly of steel sheets. These steel sheets are held together thanks to six welds equally spaced by $60^{\circ}$ on the circumference of the outer diameter as shown in Figure 2 (left). The heat generated by the welds increases the outer diameter at these six locations. As a consequence, the stator teeth located every $60^{\circ}$ are also drawn towards the outer diameter.

The second deformation of the stator is due to the assembly of the alternator. The stator is clamped between two aluminum brackets in the axial direction. Four screws hold the assembly as shown in red in Figure 2 (right). When the screws are tightened, the stator is squeezed between the two brackets and the stator is deformed. This deformation can be investigated thanks to a static mechanical simulation. Increasing pre-stress is applied on the screws to simulate their tightening and the stator is compressed. As a result of this compression, the stator adopts a square shape as shown in Figure 3.
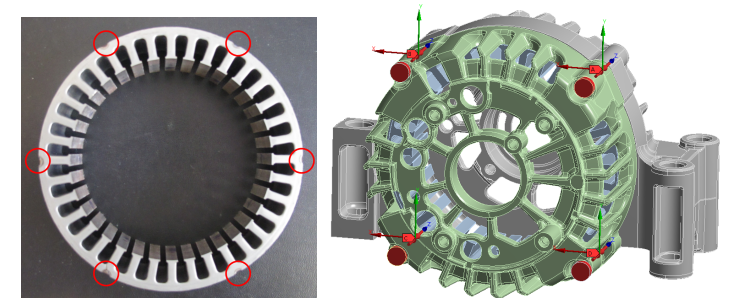

Figure 2: Stator stack with welds circled in red and statorbrackets assembly of a claw-pole alternator (screws in red)
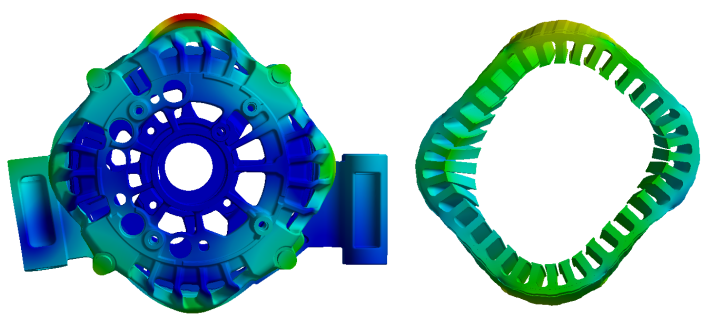

Figure 3: Stator and brackets assembly deformation and stator deformation due to the tightening of the screws

The stator deformations due to the welds and the stator and brackets assembly have been reported by Liu [8]. The measured deformed shapes of the stator inner diameter are shown in black in Figure 4. The first shape on the left is the nominal case: the inner diameter is perfectly circular. The second shape is due to the welds: six teeth are retracted, leading to an increase in the airgap width at these locations. The third shape is oval and was measured after tightening the screws. The difference between the measured oval shape and the simulated square shape may come from the successive tightening of the screws instead of a simultaneous tightening of the 4 screws as used in the simulation. The last shape on the right was measured on the inner diameter of the assembled stator and includes the oval shape due to the assembly and the retracted teeth due to the welds.

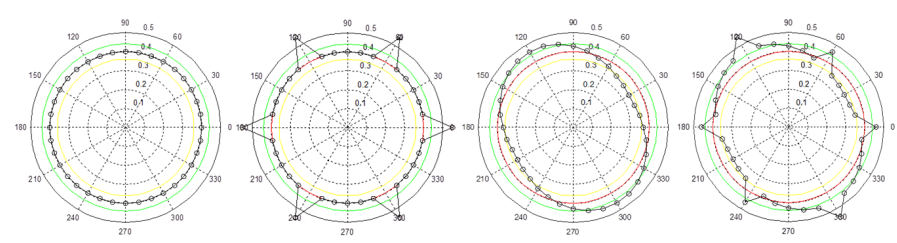

Figure 4: Inner diameter stator shapes of a claw-pole alternator in black, from left to right: nominal stator, stator with retracted teeth, oval stator, oval stator with retracted teeth [16]

The deformations of the inner diameter of the stator have an influence on the airgap width of the alternator. As a consequence, magnetic forces are affected and are investigated in the following section.

\section{Electromagnetic AND VIBRo-ACOUSTIC SIMULATION METHODS}

\section{A. Electromagnetic simulation}

Electromagnetic simulations are carried with the finite element software JMAG. The magnetic flux density and the magnetic forces can be directly computed as shown in Figure 5. However, in order to better understand the influence of the stator deformations on the magnetic forces, the analytical formulas of magnetic pressures are derived in this section.
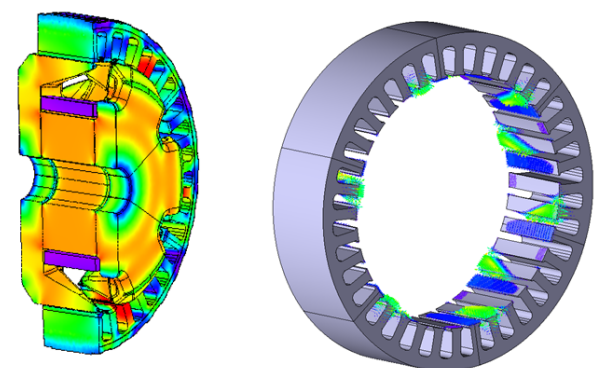

Figure 5: Magnetic flux density and magnetic forces computed with JMAG

Radial and tangential magnetic pressures, $P_{r}$ and $P_{t}$, are computed with the following formulas:

$$
\begin{gathered}
P_{r}=\frac{B_{r}^{2}-B_{t}^{2}}{2 \mu_{0}} \\
P_{t}=\frac{B_{r} B_{t}}{\mu_{0}}
\end{gathered}
$$

where $\mu_{0}$ is the magnetic permeability of vacuum and $B_{r}$ and $B_{t}$ are the radial and tangential components of the magnetic flux density. 
An analytical expression of the radial magnetic flux density $\left(B_{r}\right)$ can be derived from the magnetomotive force (mmf) and permeance $(\lambda)$ functions such as:

$$
B_{r}=m m f \times \lambda
$$

The magnetomotive force (mmf) and the permeance $(\lambda)$ functions of a claw-pole alternator must be adapted to take the rotor shape into account [11]. These equations are detailed below. First, the permeance function is written as:

$$
\lambda=\Lambda_{0}+\lambda^{s}+\lambda^{r}
$$

where $\Lambda_{0}$ is a constant value which accounts for the airgap width and $\lambda^{s}$ and $\lambda^{r}$ are the permeance functions of the stator and the rotor respectively. $\lambda^{s}$ is expressed as:

$$
\lambda^{s}=\sum_{k_{s}=1}^{\infty} \Lambda_{k s} \cos \left(k_{s} Z^{s} \alpha\right)
$$

with $Z^{s}$ the number of stator teeth and $\alpha$ the angular position.

The rotor permeance function $\lambda^{r}$ changes depending on the rotor position as shown in Figure 6. Hence, the expression of $\lambda^{r}$ includes two parameters $\alpha_{1}$ and $\alpha_{2}$ which depend on the axial position.

$\lambda^{r}=\Lambda_{0}^{r}+\sum_{k_{r}=1}^{\infty} \frac{2 \Lambda^{r}}{\pi k_{r}} \cos \left(p k_{r}(\alpha-\theta)\right) \times\left[\sin \left(p k_{r} \alpha_{1}\right)-\sin \left(p k_{r} \alpha_{2}\right)\right]$

with $p$ the number of pole pairs and:

$$
\Lambda_{0}^{r}=\frac{\alpha_{1}+\left(\pi / p-\alpha_{2}\right)}{\pi / p}
$$

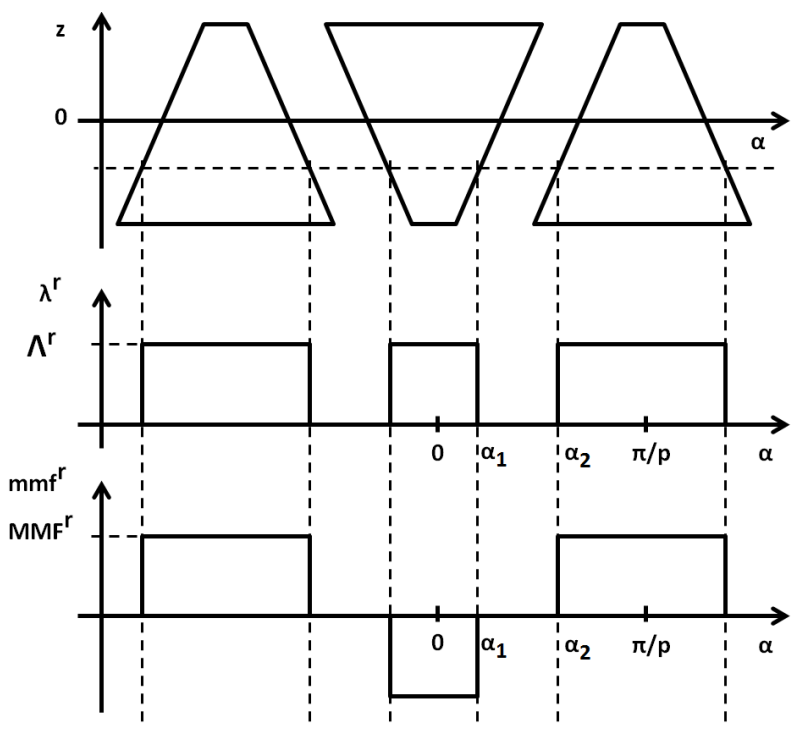

Figure 6: Magnetomotive force $m m f^{r}$ and permeance $\lambda^{r}$ of a claw-pole rotor
Magnetomotive force functions are expressed as follow with $m m f^{s}$ and $m m f^{r}$ the stator and rotor magnetomotive force functions:

$$
m m f=m m f^{s}+m m f^{r}
$$

The stator magnetomotive force function is expressed as:

$$
\begin{gathered}
m m f^{s}=\sum_{k_{s}=6 k \pm 1}^{\infty} M M F_{k s}^{s} \cos \left(p \theta \pm k_{s} p \alpha\right) \\
M M F_{k s}^{s}=\frac{3 \sqrt{2} N^{s} k_{k s}^{w} I_{k s}^{s}}{\pi p k_{s}}
\end{gathered}
$$

with $\theta$ the angular position of the rotor, $N^{s}$ the number of stator turns, $I_{k s}^{s}$ and $k_{k s}^{w}$ the RMS stator phase current and the winding factor for harmonic $k_{s}$ respectively.

Again, the rotor magnetomotive force function changes depending on the rotor position similarly to Equation 6:

$$
\begin{aligned}
m m f^{r}=M M F_{0}^{r}+ & \sum_{h_{r}=1}^{\infty} \frac{2 M M F^{r}}{\pi h_{r}} \cos \left(p h_{r}(\alpha-\theta)\right) \\
& \times\left[\sin \left(p h_{r} \alpha_{1}\right)+\sin \left(p h_{r} \alpha_{2}\right)\right]
\end{aligned}
$$

with $M M F_{0}^{r}$ and $M M F^{r}$ defined as:

$$
M M F_{0}^{r}=\frac{\alpha_{1}-\left(\pi / p-\alpha_{2}\right)}{\pi / p}
$$

$$
M M F^{r}=N^{r} I^{r}
$$

$N^{r}$ and $I^{r}$ the number of rotor turns and the rotor coil current respectively.

The stator deformations depicted in Figure 4 have an influence on the stator permeance function which must be rewritten as:

$$
\begin{array}{r}
\lambda^{s}=\sum_{k_{s}=1}^{\infty}\left(\Lambda_{k s}^{Z s} \cos \left(k_{s} Z^{s} \alpha\right)+\Lambda_{k s}^{\text {welds }}\right. \\
\left.\cos \left(6 k_{s} \alpha\right)\right) \\
+\Lambda^{\text {oval }} \cos (2 \alpha)
\end{array}
$$

with $\Lambda_{k s}^{\text {welds }}$ and $\Lambda^{\text {oval }}$ depending on the amplitudes of the stator deformations. Figure 7 shows the permeance function of a deformed 36-slots stator.

The deformations of the stator shown in Figure 4 only modify the stator permeance $\lambda^{s}$ compared to the nominal case. Since this function does not depend on $\theta$ which is a time variable but only on $\alpha$ which is a space variable, the deformations of the stator do not introduce new "temporal orders" in the magnetic forces but only new "spatial orders". As a result, the force and acoustic spectra contain the same temporal orders for all configurations (i.e. with or without deformations) but differences in amplitudes are expected. 


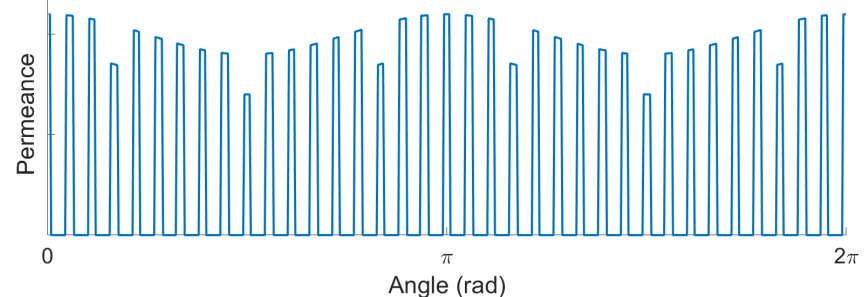

Figure 7: Permeance function of the oval stator with retracted teeth

The deformations of the stator are taken into account in the finite element model thanks to a deformation of the mesh. This method, called "morphing", consists in changing the coordinates of the nodes of a mesh. As a consequence, the mesh is only modified locally by moving the nodes close to the studied deformations as shown in Figure 8. This method avoids the introduction of possible numerical errors due to a remeshing of the complete geometry.

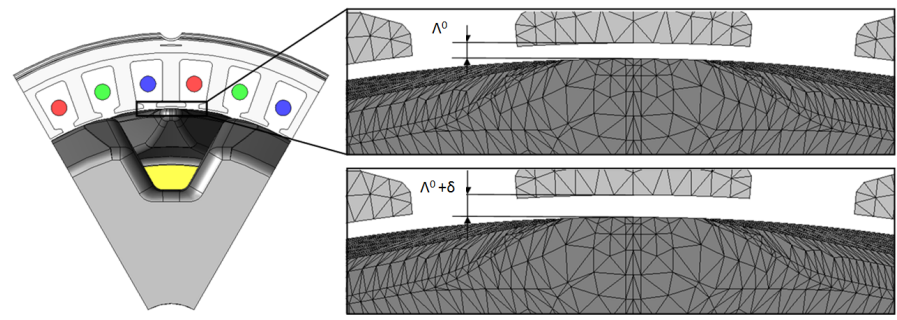

Figure 8: Mesh modification or "morphing" of a stator tooth

\section{B. Modal analysis}

The modal analysis solves the following equation:

$$
\left[K-\omega^{2} M\right]\{x\}=0
$$

with $\omega$ the angular velocity, $\{x\}$ the displacement vector and $[M]$ and $[K]$ are respectively the mass and stiffness matrices of the structure. The results of the modal analysis are the modal shapes and natural frequencies of the structure.

In order to carry out this modal analysis, a model of the structure is needed. The mechanical model of a claw-pole alternator has been detailed in [12]. This model accounts for the laminated structure of the stator stack thanks to an updated Young's modulus which is lower than for steel, meaning that the stack is less rigid than a homogeneous block of steel. The heterogeneous composition of the windings, made up with copper wires and varnish, is also accounted for with an equivalent Young's modulus assigned to a solid inside each slot. The contacts between the stator and the brackets also have to be computed. Only contacts near the screws are considered, where pressure between the stator and the brackets is maximum. The rotor is taken into account in the model and linked to the brackets with springs, modeling the stiffness of the bearings. The final model was checked against measurements of physical parts to ensure a good correlation as in [12]. Figure 9 shows an example of modal shape of the alternator obtained with ANSYS.
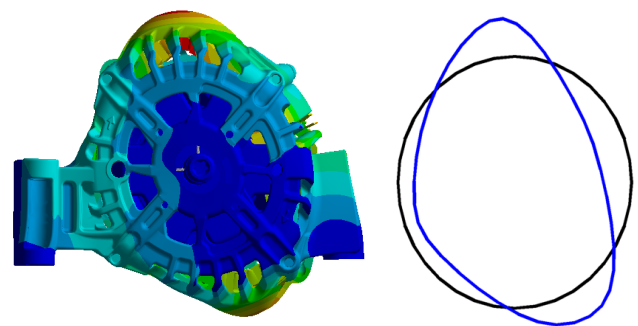

Figure 9: Simulated alternator mode shape [12]. Left: complete geometry. Right: shape of the stator outer diameter (blue) compared to its nominal shape (black)

The stator deformations due to the manufacturing process are large in comparison with the airgap width: they reach up to $40 \%$ of the airgap width. Therefore, they may have a significant influence on the magnetic forces. However, we assume that these deformations are too small to influence the mechanical dynamic behavior of the alternator. Thus, the mechanical mesh of the alternator used for the modal analysis is not deformed.

\section{Vibro-acoustic simulation}

Electromagnetic simulation and modal analysis require different mesh densities. Therefore, magnetic forces must be transferred from the electromagnetic mesh to the structural mesh. This first step of the vibro-acoustic simulation, carried out in LMS Virtual.Lab, is called "mapping". Since, the electromagnetic mesh takes the stator deformations into account and the mechanical mesh does not, the geometries of the two meshes are slightly different. However, since the deformations are much smaller than the element size of the mechanical mesh, the mapping of the forces is not affected by this difference.

Vibrations are then computed with a modal superposition method considering a $2 \%$ damping coefficient for all modes, which is a typical value for claw-pole alternators [13]. Next, sound pressures are computed based on the vibrations. The sound power of mode $m$ could be analytically calculated for a simple geometry using the following formula [14]:

$$
W_{m}=\frac{1}{2} \rho c S \sum \sigma_{m} v_{m}^{2}
$$

with $\rho$ the air density, $c$ the speed of sound in the air, $S$ the outer area of the stator, $\sigma_{m}$ the radiation factor of the stator for mode $m$ and $v_{m}$ the radial velocity.

Nonetheless, simple analytical formulas cannot be found to compute the radiation factor of parts with complex geometries such as the brackets of the alternator (see Figure 1). Hence, for claw-pole alternators, the sound power level is computed numerically with FEM. 


\section{Simulation RESUltS AND ANALYSIS}

A three-phase alternator with six pole pairs and a 36-slots stator similar to the one used in [15] is studied in this section. The four stator configurations shown in Figure 4 (nominal, oval, retracted teeth and nominal with retracted teeth) are simulated. The simulations are carried out at $4000 \mathrm{rpm}$ with an excitation current of $4 \mathrm{~A}$ and the alternator is connected to a rectifier bridge and a battery (i.e. load condition). The maximum values of the imperfections measured by Liu [16] for similar alternators are used in the simulations. The deformations reach $40 \%$ and $15 \%$ of the airgap width for the retracted teeth and oval stator respectively.

The stator deformations have an influence on the stator permeance as shown by Equation 14. As a consequence, the magnetic flux density is modified as well as the subsequent magnetic forces and acoustic noise. In the following sections, the influence of the deformations on the average torque, the output current, the magnetic forces and the sound power level (SPL) are analyzed.

\section{A. Average torque and output current}

Stator deformations change the average airgap width and influence "global" characteristics such as the average torque and output current. On the one hand, the oval shape increases and decreases the airgap width depending on the considered angular position. However, the average airgap width is the same as the nominal stator and only small changes of the average torque and output current are expected. On the other hand, the retracted teeth always increase the airgap width. Thus, the average airgap width is larger than for the nominal case and the average torque and the output current are expected to be lower. These results are confirmed by simulations as shown in Table I. In the end, stator deformations slightly decrease the global performances of the alternator.

Table I: Relative difference in average torque and output current compared with the nominal stator (for the nominal stator, torque is $-4.5 \mathrm{Nm}$ and output current is $112 \mathrm{~A}$ )

\begin{tabular}{|c|c|c|}
\hline Configuration & Average torque & Output current \\
\hline Retracted teeth & $-2.2 \%$ & $-1.6 \%$ \\
\hline Oval & $-0.3 \%$ & $-0.3 \%$ \\
\hline Oval + retracted teeth & $-0.8 \%$ & $-0.7 \%$ \\
\hline
\end{tabular}

\section{B. Magnetic forces}

In order to investigate the influence of the deformations on the magnetic forces, the sum of the forces on the stator is considered. Since tangential forces have a significant influence on the acoustic noise of claw-pole alternators as shown in [11], the forces are separated into their radial and tangential components. Instead, of summing the tangential forces on the stator, the rotor torque is considered as it is the image of the sum of the tangential magnetic forces applied on the stator. The sum of radial and tangential forces do not account for the spatial distribution of these magnetic forces, which has an important influence on the acoustic noise. However, they give a first insight into the evolution of excitation forces with the stator deformations.

Figure 10 shows the spectrum of the sum of the radial forces applied on the stator and the spectrum of the electromagnetic torque for the four simulated configurations. The temporal order 0 (i.e. null frequency) is hidden as it does not contribute to the noise generation.

The results show that the retracted teeth lead to a significant increase in amplitude of the orders multiple of 12 except for orders 36 and 72. The oval stator has relatively low influence on the magnetic forces. The results of the stator with both deformations, oval and retracted teeth, also show an increase in amplitudes of orders multiple of 12 but to a smaller extent compared with the retracted teeth alone. The ovalization seems to mitigate the effect of the retracted teeth on the sum of the radial forces and the torque.
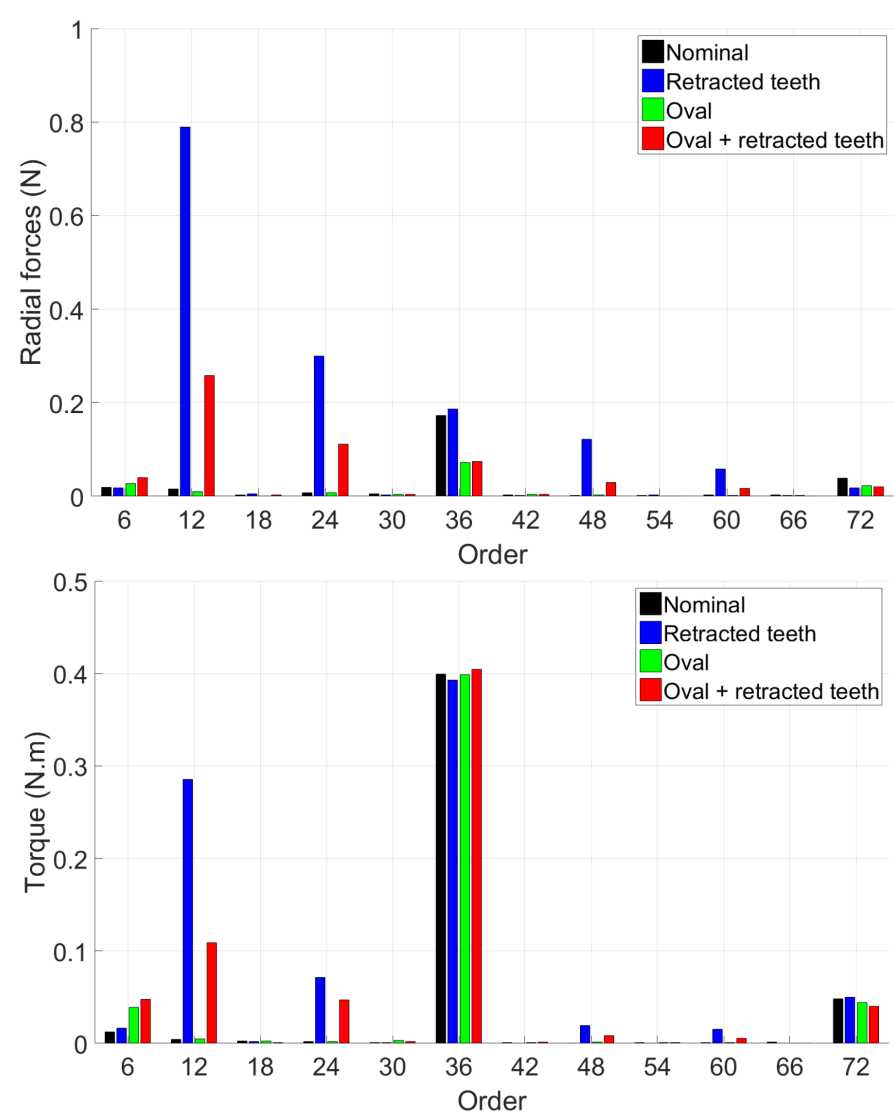

Figure 10: Spectra of the sum of radial forces acting on the stator and torque for different stators at $4000 \mathrm{rpm}$

As shown previously in [17], [18] and [19], the fundamental order of the cogging torque and the radial forces on the stator is $N^{c}$, the least common multiple $(\mathrm{lcm})$ of the number of poles $2 p$ and the number of stator teeth $Z^{s}$ :

$$
N^{c}=\operatorname{lcm}\left(2 p, Z^{s}\right)
$$


In the same manner, we can introduce $N^{w}$, the fundamental order of the forces, radial and tangential, due to the retracted teeth, defined as the least common multiple $(\mathrm{lcm})$ of the number of poles $2 p$ and the number of welds or retracted teeth $Z^{w}$ :

$$
N^{w}=\operatorname{lcm}\left(2 p, Z^{w}\right)
$$

In this case, $2 p=12$ and $Z^{w}=6$ therefore $N^{w}=12$ and the influenced orders are multiples of 12 as shown in Figure 10.

\section{Sound power level}

Figure 11 shows the sound power level (SPL) for all simulated configurations as well as the measurement. The influences of the stator deformations on the SPL are basically the same as for the magnetic forces: the influence of the ovalization is relatively small whereas the influence of the retracted teeth is significant on orders multiple of $N^{w}=12$. With the retracted teeth, the average increase in SPL for orders multiple of 12 reach about $16 \mathrm{dBA}$ compared to the nominal case.

The strong influence of the retracted teeth on the $54^{\text {th }}$ order remains unexplained by the radial forces and torque spectra. However, the difference in $\mathrm{dB}$ between the SPL of the nominal case and the retracted teeth case depicts the relative difference between these two levels. As a consequence, the difference may be large on a $\mathrm{dB}$ scale even if both values are small.

The simulated SPL with the retracted teeth and the oval shape is closer to the measurement than the simulated SPL with the nominal stator: the average difference between measurement and simulation for all the orders is $8 \mathrm{~dB}$ with the final simulation (e.g. retracted teeth and oval shape) whereas the average difference with the nominal simulation is $16.6 \mathrm{~dB}$.

The remaining discrepancies between the measurement and the simulation may be explained by other imperfections which were not taken into account. For instance, the $6^{\text {th }}$ order is not influenced by any of the simulated imperfections and is largely underestimated.

For claw-pole alternators, the SPL of the main order, in this case the $36^{\text {th }}$ order, is generally much higher than the SPL of the other orders [13]. Consequently, the stator deformations do not influence the overall sound power level. However, if one of the influenced orders, for example the $12^{\text {th }}$ or $24^{\text {th }}$ order, crosses a natural frequency meanwhile the level of $36^{t h}$ order is low, the overall SPL would be influenced.

\section{CONCLUSION}

This paper has investigated the influence of stator deformations on the acoustic noise of claw-pole alternators. First, the origins of the stator deformations have been linked to the manufacturing process. Two deformations have been studied: an oval stator shape due to the assembly of the stator

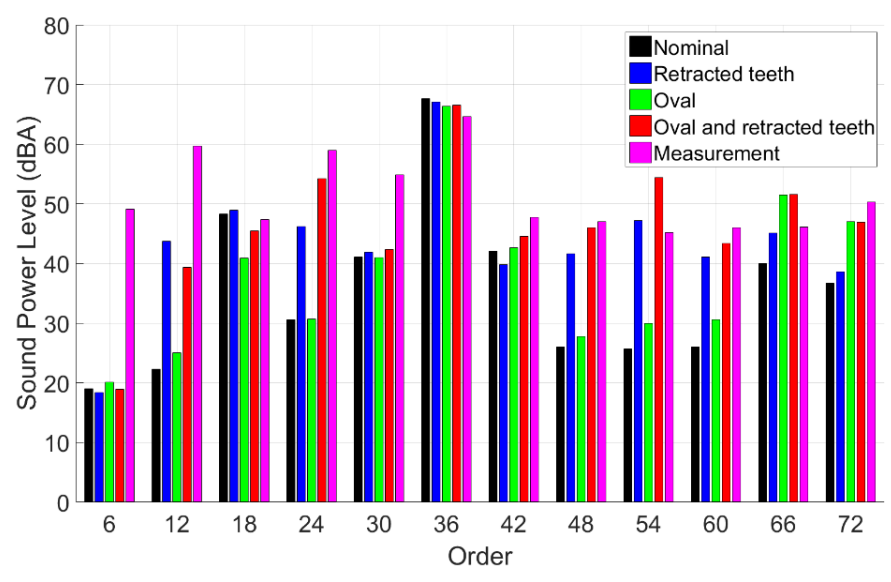

Figure 11: Sound power level spectrum of a claw-pole alternator at $4000 \mathrm{rpm}$ : simulations with different stators and measurement

in two brackets and retracted teeth at six locations due to the six welds on the stator outer diameter. The equations of the modified stator permeance were then derived to show how they affect the magnetic flux density and the magnetic forces. Simulation results show that the oval stator has little influence on the sound power level of the alternator. However, the retracted teeth have a significant influence on orders multiple of $N^{w}$, the least common multiple of the number of poles and the number of retracted teeth or welds. This influence is observed on the magnetic forces as well as on the sound power level which is increased by $16 \mathrm{dBA}$ on average. Furthermore, the simulations with the stator imperfections are much closer to the measurements compared to the simulations with the nominal stator.

In the studied case, the influence of the stator deformations on the overall sound power level (SPL) was weak. However, if the level of the influenced orders exceeds the main acoustic order, the overall SPL will also be affected. This could be the case for other electrical machines.

\section{REFERENCES}

[1] A. Tan-Kim, N. Hagen, V. Lanfranchi, S. Clénet, T. Coorevits, J. C. Mipo, J. Legranger, and F. Palleschi, "Influence of the manufacturing process of a claw-pole alternator on its stator shape and acoustic noise," in 2016 XXII International Conference on Electrical Machines (ICEM), Sept 2016, pp. 2273-2279.

[2] S. Vivier, V. Lanfranchi, and G. Friedrich, "Torque ripple improvement with IPMSM rotor shape modification," in Electrical Machines (ICEM), 2006 International Conference on, 2006.

[3] M. A. Khan, I. Husain, M. R. Islam, and J. T. Klass, "Design of experiments to address manufacturing tolerances and process variations influencing cogging torque and back EMF in the mass production of the permanent-magnet synchronous motors," IEEE Transactions on Industry Applications, vol. 50, no. 1, pp. 346-355, Jan 2014.

[4] A. J. P. Ortega, S. Paul, R. Islam, and L. Xu, "Analytical model for predicting effects of manufacturing variations on cogging torque in surface-mounted permanent magnet motors," IEEE Transactions on Industry Applications, vol. 52, no. 4, pp. 3050-3061, July 2016.

[5] F. Druesne, J. Hallal, P. Lardeur, and V. Lanfranchi, "Modal stability procedure applied to variability in vibration from electromagnetic origin for an electric motor,' Finite Elements in Analysis and Design, vol. 122 , pp. $61-74,2016$. 
[6] P. Pellerey, V. Lanfranchi, and G. Friedrich, "Numerical simulations of rotor dynamic eccentricity effects on synchronous machine vibrations for full run up," in Electrical Machines (ICEM), 2012 XXth International Conference on, sept. 2012, pp. 3008 -3014.

[7] D.-J. Kim, H.-J. Kim, J.-P. Hong, and C.-J. Park, "Estimation of acoustic noise and vibration in an induction machine considering rotor eccentricity," Magnetics, IEEE Transactions on, vol. 50, no. 2, pp. 857-860, Feb 2014.

[8] S. Liu, S. Clenet, T. Coorevits, and J. Mipo, "Influence of the stator deformation on the behaviour of a claw-pole generator," in Electrical Machines and Systems (ICEMS), 2014 17th International Conference on, oct. 2014, pp. 358-362.

[9] P. Offermann, H. Mao, T. T. Nguyen, S. Clenet, H. De Gersem, and $\mathrm{K}$. Hameyer, "Uncertainty quantification and sensitivity analysis in electrical machines with stochastically varying machine parameters," Magnetics, IEEE Transactions on, vol. 51, no. 3, pp. 1-4, March 2015.

[10] I. Ramesohl, C. Kaehler, and G. Henneberger, "Influencing factors on acoustical simulations including manufacturing tolerances and numerical strategies," in Electrical Machines and Drives, 1999. Ninth International Conference on (Conf. Publ. No. 468), 1999, pp. 142146.

[11] A. Tan-Kim, V. Lanfranchi, J. Legranger, and F. Palleschi, "A hybrid electromagnetic model for acoustic optimization of claw-pole alternators," in XVII International Symposium on Electromagnetic Fields in Mechatronics, Electrical and Electronic Engineering, 2015.

[12] A. Tan-Kim, V. Lanfranchi, S. Vivier, J. Legranger, and F. Palleschi, "Vibro-acoustic simulation and optimization of a claw-pole alternator,"
IEEE Transactions on Industry Applications, vol. 52, no. 5, pp. 3878 3885 , Sept 2016.

[13] A. Tan-Kim, "Contribution à l'étude du bruit acoustique d'origine magnétique en vue de la conception optimale de machines synchrones à griffes pour application automobile," Ph.D. dissertation, Université de Technologie de Compiègne, 2015.

[14] J. F. Gieras, J. C. Lai, and C. Wang, Noise of polyphase electric motors. CRC Press, 2005.

[15] A. Tan-Kim, V. Lanfranchi, J. Legranger, F. Palleschi, and M. Redon, "Influence of temperature on the vibro-acoustic behavior of clawpole alternators," in Electrical Machines (ICEM), 2014 International Conference on, Sept 2014, pp. 1628-1634.

[16] S. Liu, "Prise en compte des incertitudes dimensionnelles introduites par les procédés de fabrication dans les modèles numériques de machines électriques," Ph.D. dissertation, École Nationale Supérieure d'Arts et Métiers, 2015

[17] Z. Zhu and D. Howe, "Influence of design parameters on cogging torque in permanent magnet machines," Energy Conversion, IEEE Transactions on, vol. 15, no. 4, pp. 407-412, Dec 2000.

[18] L. Zhu, S. Z. Jiang, Z. Q. Zhu, and C. C. Chan, "Analytical methods for minimizing cogging torque in permanent-magnet machines," Magnetics, IEEE Transactions on, vol. 45, no. 4, pp. 2023-2031, April 2009.

[19] D. Hanselman, "Effect of skew, pole count and slot count on brushless motor radial force, cogging torque and back EMF," Electric Power Applications, IEE Proceedings -, vol. 144, no. 5, pp. 325-330, Sep 1997 